\title{
Effect of Blonanserin on Delirium in a Patient with Alzheimer Disease
}

\author{
Gaku Okugawa* \\ Department of Neuropsychiatry, Kansai Medical University Hirakata Hospital, 2-3-1 Shinmachi, Hirakata, Osaka 573- \\ 1191, Japan
}

\begin{abstract}
A 67-year-old woman with Alzheimer's disease was administered $5 \mathrm{mg}$ /day donepezil for approximately three years. The patient exhibited acute confusion, global impairment of cognition with disorientation, sleep disturbance, psychomotor agitation, hallucinations and delusions due to delirium at night. She was then administered $8 \mathrm{mg} / \mathrm{day}$ blonanserin for approximately one month in addition to donepezil. Blonanserin is an atypical antipsychotic that blocks the serotonin 5HT2A and dopamine D2 receptors. The delirium improved gradually with treatment, so the blonanserin dose was tapered to $4 \mathrm{mg} /$ day over approximately two weeks. The delirium continued to improve without adverse events. The patient continues to receive $5 \mathrm{mg}$ /day donepezil, and is able to live alone. The delirium she experienced may have been related to disturbances in neurotransmitter systems involving acetylcholine, serotonin, dopamine and gammaaminobutyric acid. Blonanserin may improve the functioning of the serotonin and dopamine neurotransmitter systems, providing effective treatment for delirium in patients with Alzheimer's disease.
\end{abstract}

Keywords: Alzheimer, blonanserin, delirium, dementia, hallucination.

\section{CASE REPORT}

A 67-year-old woman with Alzheimer disease, fulfilling DSM-IV [1] was given $5 \mathrm{mg} /$ day donepezil for about three years. She had lived alone for about 8 years after her husband died. She had no past disease history and could go shopping and clean her house before suffering this disease. She then began to have delirium at night with progressive cognitive dysfunction. She often awoke at midnight, saw men on the ceiling and heard their voices, but could not remember it the next day. Her daughter, however, who lived in the neighborhood, recognized the confusional nighttime state of the patient. She was taken to the Department of Neuropsychiatry at Kansai Medical University Hospital by her daughter. The history of the disease onset and the course of the condition were obtained from her daughter. The woman was diagnosed with having delirium with dementia because of auditory and visual hallucinations, confusion, and insomnia. Mild atrophy of the hippocampus was found bilaterally using the magnetic resonance examination. Minimental state examination (MMSE) was 17 points. The MMSE score was categorized as mild dementia. Her blood test was normal. She received blonanserin $8 \mathrm{mg} /$ day for about one month in addition to the donepezil because of the insomnia, auditory and visual hallucinations, and confusion. She was able to sleep well from the initial day of treatment for the delirium, and auditory and visual hallucinations and confusion were improved steadily by blonanserin. The delirium improved without side effects. Then the dose was tapered to $4 \mathrm{mg}$ /day once before dinner for about 2 weeks. Subsequently, she received only donepezil $5 \mathrm{mg} /$ day, after *Address correspondence to this author at the Department of
Neuropsychiatry, Kansai Medical University Hirakata Hospital, 2-3-1
Shinmachi, Hirakata, Osaka 573-1191, Japan; Tel: +81-72-804-0101; Fax:
+81-72-804-0166; E-mail: okugwa@hirakata.kmu.ac.jp which the delirium resolved completely. She now lives in her house alone and continues to take donepezil $5 \mathrm{mg} / \mathrm{day}$ without delirium recurrence.

\section{DISCUSSION}

This is the first report in the international literature of blonanserin improving delirium with Alzheimer disease. Haloperidol is the standard treatment for delirium in elderly people [2]. It is a typical antipsychotic drug which predominantly blocks D2 receptors. Risperidone is an antipsychotic drug which blocks 5HT2A, D2, and noradrenalin $\alpha 1$ receptors [3]. It is also effective for the treatment of delirium in elderly people [4]. Blonanserin is an atypical antipsychotic drug for treatment of patients with schizophrenia [5]. It was developed by a Japanese pharmaceutical company (Dainippon-Sumitomo Pharmaceutical Co. Ltd.), and in 2008, it was approved for prescription in Japan. It preferentially blocks dopamine D2 receptors as well as serotonin 5HT2 receptors, and does not affect gamma-aminobutyric acid, acetylcholine or cytokines. It is classified in Japan as a dopamine-serotonin antagonist. The potential beneficial tolerability of the drug in short-term trials included fewer extrapyramidal symptoms than haloperidol [5]. Therefore, it is easier to prescribe in elderly patients.

The patient exhibited acute confusion, global impairment of cognition with disorientation, disturbance in sleep, psychomotor agitation, hallucination, and delusion as delirium symptoms. Because the patient did not remember the episodes at all the next day, it was very important to obtain the history of the onset and course of the condition from her family [6]. The risk factors for delirium may have been advanced age and dementia in this case. The patient did not show delirium after the episode while being treated with a cholinesterase inhibitor, donepezil. The neurotransmitters 
acetylcholine and serotonin may play important roles in the mechanism underlying delirium. Dopamine and gammaaminobutyric acid may be involved in the development of delirium [7]. Delirium is considered to be the final common symptom of multiple neurotransmitter abnormalities [8]. According to the neurotransmitter hypothesis of delirium, there is reduced cholinergic function, excess release of dopamine, norepinephrine, and glutamate, decreased serotonergic activity and increased gamma-aminobutyric acid activity in the brain [9]. A possible reason for the patient's neurotransmitter abnormalities may have been progression of Alzheimer disease. Because blonanserin blocks dopamine D2 receptors and 5HT2A receptors, it is possible that blonanserin was effective for the treatment of delirium because it improved dopamine and serotonin neurotransmitter abnormalities. We need additional cases to clarify the mechanism by which blonanserin improves delirium in Alzheimer disease.

\section{CONCLUSION}

This case report suggests that blonanserin may be effective for the treatment of delirium in patients with
Alzheimer disease, and have the added benefit of good tolerability.

\section{REFERENCES}

[1] American Psychiatric Association. Diagnostic and statistical manual of mental disorders. $4^{\text {th }}$ ed. Washington, DC: American Psychiatric Association Press 2000.

[2] Leentjens AF, van der Mast RC. Delirium in elderly people: an update. Curr Opin Psychiatry 2005; 18: 325-30.

[3] Grant S, Fitton A. Risperidone. A review of its pharmacology and therapeutic potential in the treatment of schizophrenia. Drug 1994; 48: 253-73.

[4] Ozbolt LB, Paniagua MA, Kaiser RM. Atypical antipsychotics for the treatment of delirious elders. J Am Med Dis Assoc 2008; 9: 1828.

[5] Deekes Ed, Keating GM. Blonanserin: a review of its use in the management of schizophrenia. CNS Drug 2010; 24: 65-84.

[6] Gleason OC. Delirium. Am Fam Physician 2003; 67: 1027-34.

[7] Flacker JM, Lipsitz LA. Neural mechanisms of delirium: current hypotheses and evolving concepts. J Gerontol A Biol Med Sci 1999; 54: B239-46.

[8] van der Mast RC, Fekkes D. Serotonin and amino acids: partners in delirium pathophysiology? Semin Clin Neuropsychiatry 2000; 5: 125-31.

[9] van der Mast RC. Pathophysiology of delirium. J Geriatr Psychiatry Neurol 1998; 11: 138-145; discussion 157-8. 